\title{
Implementation and monitoring of decisions by Pharmacy and Therapeutics Committees in South African public sector hospitals
}

\author{
Tsakane P. Mashaba MPharm¹, Moliehi Matlala PhD¹, Brian Godman PhD ${ }^{1,2,3,4}$, Johanna C. Meyer \\ $\mathrm{PhD}^{1}$ \\ 1Department of Public Health Pharmacy and Management, School of Pharmacy, Sefako Makgatho \\ Health Sciences University, Garankuwa, South Africa. Emails: tsakanepmashaba@gmail.com; \\ moliehi.matlala@smu.ac.za; hannelie.meyer@smu.ac.za \\ ${ }^{2}$ Strathclyde Institute of Pharmacy and Biomedical Sciences, Strathclyde University, Glasgow, UK. \\ Email: Brian.godman@strath.ac.uk \\ ${ }^{3}$ Department of Laboratory Medicine, Division of Clinical Pharmacology, Karolinska Institutet, \\ Karolinska University Hospital Huddinge, Stockholm, Sweden. Email: Brian.Godman@ki.se \\ ${ }^{4}$ Health Economics Centre, University of Liverpool Management School, Liverpool, UK. Email: \\ Brian.Godman@liverpool.ac.uk
}

Author for correspondence: Moliehi Matlala, School of Pharmacy, Sefako Makgatho Health Sciences University, Garankuwa, South Africa. Email: moliehi.matlala@smu.ac.za. Tel: 0125214741.

(Accepted for publication in Expert Review of Clinical Pharmacology - Please keep Confidential)

\begin{abstract}
Introduction: The National Drug Policy in South Africa has achieved its objective in establishing and strengthening Pharmacy and Therapeutics Committees (PTCs) in all hospitals. However, little is known about the implementation of decisions by PTCs and the monitoring thereof. Consequently, a need to investigate this. Areas covered: We sought to address this via an online survey distributed to pharmacists working in public sector hospitals across South Africa with perceived functioning PTCs, with a $32.3 \%$ response rate to the survey. Expert commentary: Membership of all PTCs included a pharmacist, who in most cases $(51.2 \%)$ held the secretariat position. Principal PTC activities were encouraging rational medicine use (RMU) $(86.0 \%)$, pharmacovigilance $(82.6 \%)$ and implementing standard treatment guidelines (STGs) $(77.9 \%)$. Only a third (37.5\%) stated that they were using indicators to monitor PTC performance. Where collected, indicator data were mostly used for providing feedback to PTCs (83.3\%). Most hospitals (95.1\%) implemented PTC decisions; however, $62.0 \%$ mentioned guidelines on implementing PTC decisions did not exist in their hospital. The majority of respondents $(65.4 \%$ and $83.8 \%$ respectively) indicated PTC decisions were evaluated and reviewed in their hospitals. Overall a high percentage of respondents stated the main activities of PTCs were to enhance RMU as well as implement STGs. However, guidelines on implementation of decisions by PTCs are currently lacking and most PTCs were not monitoring their performance. This needs to be addressed.
\end{abstract}

Keywords: Pharmacy and Therapeutics Committee, Hospitals, Indicators, decision implementation, South Africa

\section{Background}

The establishment of Pharmacy and Therapeutics Committees (PTCs) has been advocated by the World Health Organization (WHO) as one of the focal models to promote rational medicine use (RMU) [1]. The rational use of medicines can be achieved through promoting rational prescribing, dispensing and use of medicines, by health care professionals, together with supporting informed and appropriate use of medicines by the community [2]. PTCs have worked well across countries to improve the quality and efficiency of prescribing [3-6], given concerns with promotional activities of pharmaceutical companies across countries, including low and middle-income countries [7-11].

One of the goals of the South African Government is to ensure reliable supply of medicines in adequate quantities so that the entire population, at all times, have access to safe, high quality, costeffective medicines [2]. Furthermore, the rational use of medicines by prescribers, dispensers and consumers must be ensured [2]. For this goal to be achieved, the South African National Drug Policy has as one of its objectives to establish and strengthen PTCs in all hospitals (both public and private sector) $[2,16]$. PTCs play a role by being committed to the governance of an effective medicines management system in order to provide equitable and reliable access to medicines and quality care, 
while making the best use of available resources [17]. However, there have been concerns with the prescribing of medicines in hospitals in South Africa [12-15]. To help address concerns, and ensure efficient, rational and cost-effective supply and use of medicines, a system to effectively manage medicine use across all sectors needs to be in place, which includes a functioning PTC in hospitals [17].

More recently, in 2015, a National Policy for the Establishment and Functioning of Pharmaceutical and Therapeutics Committees in South Africa was published [17]. The previous lack of a coherent policy for PTCs resulted in differences in the objectives and functioning of PTCs across and within the same level of care in South Africa [19]. However, a number of initiatives are currently under development including directives on the functioning of PTCs [18].

As mentioned, PTCs were developed to maximize RMU, especially in hospitals, through consideration of the safety and effectiveness of different medicines to treat different conditions. However, PTCs have evolved since their inception in terms of decision making processes around evaluating and promoting RMU, including physician education, auditing current prescribing, monitoring adverse drug reactions (ADRs), committee membership and responsibilities [3, 20, 21]. In some countries, for example Laos, the tasks of PTCs also included the development of medicine policies, evaluating and selecting medicines for the formulary list, developing, adapting and implementing standard treatment guidelines (STGs), assessing medicine use to identify problems, conducting interventions to improve medicine use against STGs, managing ADRs and rectifying medication errors [22]. Within South Africa in general, there are concerns with the level of reporting of ADRs and medication errors in hospitals, as well as lack of evidence-based decision making in formulary management, with ongoing activities to try and address this [18, 23-25].

Objective patient and institution centered factors should ideally guide decisions taken by PTCs, including comparative efficacy and cost-benefit analysis of the chosen medicines $[4,18,26]$. Whilst PTC activities in South Africa typically include dissemination of decisions and formulary management, reporting of ADRs and medication errors is typically poor [12]. Furthermore, it is not totally clear how decisions made by most PTCs have been implemented and no indication of whether the outcomes of PTC decisions are being evaluated [12]. This is a concern, as evaluation provides feedback on the outcomes of activities such as changes in prescribing behavior, whether agreed plans and objectives regarding medicine use are being met and the reasons for success or failure. Evaluation should also provide direction for future pragmatic plans [27].

Moreover, according to recommendations from the WHO, the organizational development and performance of the PTC should be monitored continuously and be documented using indicators, which are considered to be core parameters of its goals and objectives [22]. Process, impact and outcome indicators can be used to measure the functionality of local PTCs repeatedly, and identify when a PTC is effective and making an impact [28]. However to date, there has been limited published data regarding the performance and methods used by PTCs in South Africa to implement their decisions. We recently published on the activities of PTCs in public hospitals in the Gauteng Province in South Africa, including current concerns [12]. Consequently, the aim of this study was to build on this and investigate the implementation and monitoring of decisions by PTCs among public sector hospitals with functioning PTCs, across South Africa. Public sector hospitals were targetted for this research as they manage the vast majority (over $80 \%$ ) of patients in South Africa [18].

\section{Materials and Methods}

\subsection{Study design and target population}

The study employed a descriptive survey design using a quantitative research approach. An electronic questionnaire was emailed to a pharmacist, who would normally participate in the hospital PTC, in public sector hospitals across South Africa. At the time of the study, there were 412 public sector hospitals in the nine provinces of South Africa, including district hospitals, regional hospitals, tertiary hospitals, central and specialized hospitals.

\subsection{Study population and sample}

Inclusion criteria for participation in the study were i) hospitals with a pharmacy; iii) hospitals with a pharmacist that could be reached by phone and by email; and iii) hospitals with a functioning PTC. Hospitals were first contacted via the telephone to verify eligibility for the study and obtain the email 
address of the pertinent pharmacist to contact for the survey. At the time of the study, $8(1.9 \%)$ of the 412 public sector hospitals did not have a pharmacy and 35 (8.5\%) did not have a functioning PTC. Furthermore, in the case of $90(21.8 \%)$ hospitals, either the hospital or the pharmacist could not be reached at all, and in $11(2.7 \%)$ hospitals, email invitations were undelivered. This resulted in a sample of 268 public sector hospitals in South Africa where the pharmacist was invited to participate in the study.

\subsection{Questionnaire design and data collection}

A questionnaire, using the electronic platform SurveyMonkey ${ }^{\circledR}$, was developed from questionnaires used in previous studies [12, 20,29]. The questionnaire was reviewed for content and face validity by two expert consultants, who previously provided support to PTCs and had considerable experience with, and knowledge of, the functioning of PTCs. Following this expert review, the questionnaire was modified, with additional questions added, to enhance its robustness.

The questionnaire included close-ended, open-ended, Likert scale and rating scale questions. Data were collected over a period of four months in 2017. After the pharmacist was contacted telephonically, he/she was emailed an invitation with a link to access and respond to the questionnaire online. Supporting documents, providing information about the study, ethical clearance and permission from authorities, were attached to the invitation. All participants were reminded about the survey vial email, with a request for those who had already completed the questionnaire to ignore the reminders. This methodology was undertaken because SurveyMonkey ${ }^{\circledR}$ does not keep a record of email addresses from which completed questionnaires are sent, therefore ensuring anonymity. An initial reminder was sent after a month, followed by 2-weekly reminders in the second month and weekly reminders in the last two months (17 reminders in total), after which the survey closed.

An online electronic survey was regarded the most appropriate method to distribute the questionnaire and collect the data, considering i) the size of the country; ii) the study being conducted in all nine provinces; and iii) lack of available manpower and finances to travel and administer the questionnaire using face-to-face interviews. Advantages of web-based questionnaires are that they can speed-up the process, reach as many potential interviewees as possible as well as remove some of the bottlenecks associated with more traditional approaches [30, 31], however, recognizing that response rates may not be as high as with paper-based surveys [32].

\subsection{Data analysis}

Data were exported from SurveyMonkey ${ }^{\circledR}$ to Microsoft Office Excel ${ }^{\mathrm{TM}}$, cleaned, coded and then imported into Statistical Package for the Social Sciences (SPSS) version 24 for analysis. Descriptive statistics were used to summarise categorical variables as frequency counts and percentages. Open ended responses were manually categorised to allow frequency and percentage calculation.

\subsection{Ethical considerations}

Ethical clearance was obtained from Sefako Makgatho University Research Ethics Committee (SMUREC/H/171/PG: 2016) and permission to conduct the study was granted by the National and Provincial Departments of Health and the management from individual hospitals. The questionnaire was completed anonymously and contained a consent statement, stating that completion of the questionnaire consequently implied consent. Participation in the study was entirely voluntarily upon receiving the link to the survey and the supporting documents.

\section{Results}

\subsection{Response rate}

After four months, 86 of the 268 emailed and delivered questionnaires were returned, which resulted in a response rate of $32.1 \%$. Two (0.7\%) pharmacists declined participation and $180(67.2 \%)$ did not respond. Table 1 shows a summary of the target population and the study population per province. Not all participants responded to all questions in the questionnaire, hence the difference in sample size in the presentation of the results. 
Table 1: Target population, study population and response rate per province

\begin{tabular}{|c|c|c|c|c|c|c|c|c|c|}
\hline \multirow[b]{2}{*}{ Province } & \multirow{2}{*}{$\begin{array}{c}\text { Target } \\
\text { populati } \\
\text { on } \\
(n=412)\end{array}$} & \multicolumn{4}{|c|}{ Excluded from target population } & \multirow{2}{*}{$\begin{array}{c}\text { Email } \\
\text { invitatio } \\
n \\
\text { delivere } \\
d\end{array}$} & \multicolumn{3}{|c|}{ Study population $(\mathrm{n}=268)$} \\
\hline & & $\begin{array}{c}\text { No } \\
\text { pharmacy }\end{array}$ & $\begin{array}{l}\text { No } \\
\text { PTC }\end{array}$ & $\begin{array}{l}\text { No email } \\
\text { address } \\
\text { obtained }\end{array}$ & Undelivered & & $\begin{array}{c}\text { Declined } \\
\text { participatio } \\
\mathbf{n}\end{array}$ & $\begin{array}{c}\text { Non- } \\
\text { responses }\end{array}$ & $\begin{array}{l}\text { Response } \\
\text { rate }\end{array}$ \\
\hline Eastern Cape & 91 & 1 & 16 & 25 & 1 & 48 & $1(1.1 \%)$ & $32(68.1 \%)$ & $15(31.9 \%)$ \\
\hline Free State & 32 & 0 & 4 & 6 & 3 & 19 & $0(0.0 \%)$ & $14(73.7 \%)$ & $5(26.3 \%)$ \\
\hline Gauteng & 34 & 0 & 0 & 4 & 2 & 28 & $0(0.0 \%)$ & $20(71.4 \%)$ & $8(28.6 \%)$ \\
\hline KwaZulu Natal & 72 & 1 & 1 & 13 & 3 & 54 & $1(1.4 \%)$ & $33(62.3 \%)$ & $20(37.7 \%)$ \\
\hline Limpopo & 41 & 0 & 0 & 3 & 1 & 37 & $0(0.0 \%)$ & $25(67.6 \%)$ & $12(32.4 \%)$ \\
\hline Mpumalanga & 34 & 0 & 0 & 12 & 0 & 22 & $0(0.0 \%)$ & $17(77.3 \%)$ & $5(22.7 \%)$ \\
\hline Northern Cape & 22 & 1 & 10 & 7 & 0 & 4 & $0(0.0 \%)$ & $4(100 \%)$ & $0(0.0 \%)$ \\
\hline North West & 27 & 0 & 1 & 3 & 1 & 22 & $0(0.0 \%)$ & $10(45.5 \%)$ & $12(54.5 \%)$ \\
\hline Western Cape & 59 & 5 & 3 & 17 & 0 & 34 & $0(0.0 \%)$ & $26(76.5 \%)$ & $8(13.6 \%)$ \\
\hline Unspecified $^{*}$ & - & - & - & - & - & - & - & $(-1)$ & 1 \\
\hline $\begin{array}{c}\text { Total number } \\
(\%)\end{array}$ & 412 & $\begin{array}{l}8 \\
(1.9 \%)\end{array}$ & $\begin{array}{c}35 \\
(8.5 \% \\
)\end{array}$ & $\begin{array}{c}90 \\
(21.8 \%)\end{array}$ & $\begin{array}{c}11 \\
(2.7 \%)\end{array}$ & 268 & $\begin{array}{c}2 \\
(0.7 \%)\end{array}$ & $\begin{array}{c}180 \\
(67.2 \%)\end{array}$ & $\begin{array}{c}86 \\
(32.1 \%)\end{array}$ \\
\hline
\end{tabular}

*Participant did not indicate a province; therefore, the total number of non-responses cannot be concluded

\subsection{Characteristics of sample population}

Table 2 shows the characteristics of the participating hospitals and the respective pharmacists who participated in the survey. Nearly two-thirds $(60.5 \%)$ of the participating hospitals were district hospitals. Bed capacity varied between $\leq 100$ beds (23.4\%), 101-200 beds (22.1\%), and $201-400$ beds $(27.9 \%)$ to more than 400 beds $(26.7 \%)$. For a third of the respondents $(33.7 \%)$, the PTC at their hospital had been in existence for $\leq 5$ years.

Of the 86 respondents, $55.8 \%$ were female. The majority ( $81.4 \%)$ of the pharmacists' highest qualification was a Bachelor of Pharmacy (BPharm) degree, with only $12(14.0 \%)$ having a postgraduate qualification. More than half $(55.3 \%)$ of pharmacists held a managerial cadre position in the hospital. Half of the respondents had $\leq 10$ years of experience as a practicing pharmacist and one third had served $\leq 5$ years on the PTC at their current hospital. Most participants had between 0-5 years' experience in their hospital's PTC (Table 2). 
Table 2: Characteristics of participating hospitals and their respective pharmacists $(n=86)$

\begin{tabular}{|c|c|c|}
\hline & \multirow{2}{*}{$\begin{array}{c}\text { Number (\%) } \\
52(60.5 \%)\end{array}$} \\
\hline \multicolumn{2}{|c|}{$\begin{array}{l}\text { Characteristics of participating hospital and pharmacist }(\mathbf{n}=86) \\
\text { Hospital level of care }\end{array}$} & \\
\hline & Regional (Level 2) & $16(18.6 \%)$ \\
\hline & Tertiary (Level 3) & $7(8.1 \%)$ \\
\hline & National & $1(1.2 \%)$ \\
\hline & Specialised & $10(11.6 \%)$ \\
\hline \multirow[t]{8}{*}{ Hospital bed capacity } & $\leq 100$ & $20(23.4 \%)$ \\
\hline & $101-200$ & $19(22.1 \%)$ \\
\hline & $201-400$ & $24(27.9 \%)$ \\
\hline & $401-600$ & $5(5.8 \%)$ \\
\hline & $601-800$ & $4(4.7 \%)$ \\
\hline & $801-1000$ & $4(4.7 \%)$ \\
\hline & $>1000$ & $1(1.2 \%)$ \\
\hline & Other & $9(10.2 \%)$ \\
\hline \multirow[t]{8}{*}{ Number of years current PTC in existence } & $\leq 5$ & $29(33.7 \%)$ \\
\hline & $6-10$ & $22(25.6 \%)$ \\
\hline & $11-15$ & $12(14.0 \%)$ \\
\hline & $16-20$ & $3(3.5 \%)$ \\
\hline & $21-25$ & $1(1.2 \%)$ \\
\hline & $26-30$ & $3(3.5 \%)$ \\
\hline & $>30$ & $1(1.2 \%)$ \\
\hline & Other & $15(17.3 \%)$ \\
\hline \multirow[t]{5}{*}{ Age (years) } & $\leq 30$ & $17(19.8 \%)$ \\
\hline & $31-40$ & $42(48.8 \%)$ \\
\hline & $41-50$ & $13(15.1 \%)$ \\
\hline & $51-60$ & $12(14.0 \%)$ \\
\hline & $>60$ & $2(2.3 \%)$ \\
\hline \multirow[t]{5}{*}{ Professional qualification } & BPharm & $70(81 . \%)$ \\
\hline & MPharm & $9(11 \%)$ \\
\hline & PharmD & $2(2 . \%)$ \\
\hline & $\mathrm{PhD}$ & $1(1 . \%)$ \\
\hline & No response & $4(5 \%)$ \\
\hline \multirow[t]{6}{*}{ Years of practice as a pharmacist } & $\leq 10$ & $43(50.0 \%)$ \\
\hline & $11-20$ & $21(24.4 \%)$ \\
\hline & $21-30$ & $14(16.3 \%)$ \\
\hline & $31-40$ & $5(5.8 \%)$ \\
\hline & $>40$ & $1(1.2 \%)$ \\
\hline & No response & $2(2.3 \%)$ \\
\hline \multirow[t]{4}{*}{ Position in hospital } & Managerial cadre & $47(55.3 \%)$ \\
\hline & Senior pharmacist & $37(43.5 \%)$ \\
\hline & Junior pharmacist & $1(1.2 \%)$ \\
\hline & Other & $1(1.2 \%)$ \\
\hline \multirow[t]{6}{*}{ Number of years serving on current PTC } & $0-5$ & $51(59.3 \%)$ \\
\hline & $6-10$ & $16(18.6 \%)$ \\
\hline & $11-15$ & $11(12.8 \%)$ \\
\hline & $16-20$ & $1(1.2 \%)$ \\
\hline & $21-25$ & $1(1.2 \%)$ \\
\hline & Other & $6(6.9 \%)$ \\
\hline \multirow[t]{6}{*}{ Number of years experience in PTC } & $0-5$ & $43(50.0 \%)$ \\
\hline & $6-10$ & $20(23.3 \%)$ \\
\hline & $11-15$ & $13(15.1 \%)$ \\
\hline & $16-20$ & $5(5.8 \%)$ \\
\hline & $21-25$ & $1(1.2 \%)$ \\
\hline & Other & $4(4.6 \%)$ \\
\hline \multirow[t]{7}{*}{ Position in PTC } & Secretariat & $44(51.2 \%)$ \\
\hline & Chairperson & $17(19.8 \%)$ \\
\hline & Member or pharmacy representative & $13(15.1 \%)$ \\
\hline & Deputy chairperson & $2(2.3 \%)$ \\
\hline & Chairperson and secretariat & $2(2.3 \%)$ \\
\hline & Primary health care pharmacist & $1(1.2 \%)$ \\
\hline & Advisory pharmacist & $1(1.2 \%)$ \\
\hline
\end{tabular}




\begin{tabular}{|c|c|c|}
\hline \multicolumn{2}{|c|}{ Characteristics of participating hospital and pharmacist ( $\mathbf{n = 8 6 )}$} & Number (\%) \\
\hline & Pharmacovigilance and AMS champion & $1(1.2 \%)$ \\
\hline & Secretariat and AMS chairperson & $1(1.2 \%)$ \\
\hline
\end{tabular}

AMS: Antimicrobial stewardship

\subsection{Structure of PTCs and meetings}

The composition of the PTC included in the majority of cases a medical practitioner (97.6\%), pharmacist $(100 \%)$ and a nurse $(97.6 \%)$. Administrative officers had a $25.6 \%$ representation on the PTCs. The size of the PTCs reported in the hospitals taking part in the survey, ranged between 11-15 members in $30.2 \%$ of cases, $16-20$ in $20.9 \%$, and $21-25$ members in $20.9 \%$ of cases. Table 3 shows that pharmacists' representation in their hospital PTC was usually as the secretariat $(51.2 \%)$ and among $19.8 \%$ of the PTCs the pharmacists were the chairperson.

Table 3: Pharmacist's position in the hospital PTC

\begin{tabular}{|l|l|}
\hline Position in hospital PTC & Number $(\%)(\mathrm{n}=86)$ \\
\hline Secretariat & $44(51.2 \%)$ \\
\hline Chairperson & $17(19.8 \%)$ \\
\hline Member/pharmacy representative & $13(15.1 \%)$ \\
\hline Deputy chairperson & $2(2.3 \%)$ \\
\hline Chairperson and secretariat & $2(2.3 \%)$ \\
\hline Primary health care pharmacist & $1(1.2 \%)$ \\
\hline Advisory pharmacist & $1(1.2 \%)$ \\
\hline Pharmacovigilance and antimicrobial stewardship champion & $1(1.2 \%)$ \\
\hline Secretariat and antibiotic stewardship chairperson & $1(1.2 \%)$ \\
\hline
\end{tabular}

The number of PTC meetings held annually ranged between four and 12 times a year. PTC meetings were typically held either monthly $(47.9 \%)$ or every quarter $(47.9 \%)$. The number of PTC members required for a quorum ranged between $6-10$ members $(37.2 \%)$ and $11-15$ members $(14 \%)$. In $37.2 \%$ of hospitals, 5-10 members would typically attend the PTC meetings, followed by $11-15$ members in $32.6 \%$ of the hospitals.

According to the respondents, a quorum was met in the majority of PTC meetings, either always $(37.5 \%)$ or often $(41.3 \%)$. Four $(5.0 \%)$ respondents indicated that they did not know how often their PTC meeting reached a quorum.

\subsection{Functions and responsibilities of PTCs}

The primary functions of the PTC in most hospitals $(86,0 \%)$ as presented in Table 4 were ensuring the rational use of medicines, specifically medicine use evaluation and medicine use review. This was the case at all levels of care, with $100 \%$ of the tertiary hospital and $90.0 \%$ of the specialised hospital respondents confirming this function. Pharmacovigilance, with reference to the management of ADRs, handling of product complaints and medication errors was also common (82.6\%), as was implementing STGs (77.9\%). Overall $72.1 \%$ of hospital PTCs had antimicrobial stewardship (AMS) programmes in place with specialized hospitals and district hospitals being the lowest, with two thirds (60.0\% and $67.3 \%$ respectively) reporting that they have AMS programmes. 
Table 4: Functions of the PTC

\begin{tabular}{|c|c|c|c|c|c|c|}
\hline Function & $\begin{array}{c}\begin{array}{c}\text { District } \\
(\mathrm{n}=52)\end{array} \\
\end{array}$ & $\begin{array}{c}\text { Regional } \\
(n=16)\end{array}$ & $\begin{array}{c}\text { Tertiary } \\
(\mathrm{n}=7)\end{array}$ & $\begin{array}{c}\text { Central } \\
(n=1)\end{array}$ & $\begin{array}{c}\text { Specialised } \\
(n=10)\end{array}$ & $\begin{array}{c}\text { Total } \\
(n=86)\end{array}$ \\
\hline $\begin{array}{l}\text { Rational medicine use (Medicine } \\
\text { use evaluation; medicine use } \\
\text { review) }\end{array}$ & $4(82.7 \%)$ & $14(87.5 \%)$ & $7(100.0 \%)$ & $1(100 \%)$ & $9(90.0 \%)$ & $7(86.0 \%)$ \\
\hline $\begin{array}{l}\text { Pharmacovigilance (Management } \\
\text { of adverse drug reactions; product } \\
\text { complaints; medication errors) }\end{array}$ & $41(78.8 \%)$ & $14(87.5 \%)$ & $6(85.7 \%)$ & $1(100 \%)$ & $9(90.0 \%)$ & $71(82.6 \%)$ \\
\hline $\begin{array}{l}\text { Implementing Standard Treatment } \\
\text { Guidelines }\end{array}$ & $43(82.7 \%)$ & $12(75.0 \%)$ & $5(71.4 \%)$ & $1(100 \%)$ & $6(60.0 \%)$ & $67(77.9 \%)$ \\
\hline Antibiotic stewardship & $35(67.3 \%)$ & $13(81.3 \%)$ & $7(100.0 \%)$ & $1(100 \%)$ & $6(60.0 \%)$ & $62(72.1 \%)$ \\
\hline $\begin{array}{l}\text { Prepare and monitor a budget for } \\
\text { medicines }\end{array}$ & $30(57.7 \%)$ & $9(56.3 \%)$ & $4(57.1 \%)$ & $1(100 \%)$ & $5(50.0 \%)$ & $49(57.0 \%)$ \\
\hline $\begin{array}{l}\text { Develop and maintain medicines } \\
\text { formularies }\end{array}$ & $24(46.2 \%)$ & $12(75.0 \%)$ & $5(71.4 \%)$ & $1(100 \%)$ & $4(40.0 \%)$ & $46(53.5 \%)$ \\
\hline $\begin{array}{l}\text { Monitoring and reporting on } \\
\text { above; Enforce compliance to the } \\
\text { Good Pharmacy Practice and } \\
\text { legal requirements }\end{array}$ & & & $1(14.3 \%)$ & & & $1(1.2 \%)$ \\
\hline $\begin{array}{l}\text { New drugs needed; adverse drug } \\
\text { reactions; prescriber levels }\end{array}$ & & $1(6.3 \%)$ & & & & $1(1.2 \%)$ \\
\hline $\begin{array}{l}\text { Antibiotic stewardship is a } \\
\text { separate committee }\end{array}$ & & $1(6.3 \%)$ & & & & $1(1.2 \%)$ \\
\hline $\begin{array}{l}\text { Inform of pharmacy stock outs } \\
\text { and alternative treatment }\end{array}$ & $1(1.9 \%)$ & & & & & $1(1.2 \%)$ \\
\hline $\begin{array}{l}\text { ABC and VEN analysis; blood and } \\
\text { blood products }\end{array}$ & $1(1.9 \%)$ & & & & & $1(1.2 \%)$ \\
\hline
\end{tabular}

\subsection{Monitoring of PTC performance}

Of the 86 respondents, 80 completed this section of the questionnaire. Only $37.5 \%$ of respondents stated that they were using monitoring and evaluation indicators to monitor the PTC performance. The most common reasons for not using indicators are provided in Table 5 and include people not being aware of indicators (66.0\%), which was the case for all respondents from the regional- and specialized hospitals. Another reason cited by $36.2 \%$ of hospitals, was lack of time (Table 5). 
Table 5: Availability of and the use of performance indicators by PTCs

\begin{tabular}{|c|c|c|c|c|c|c|}
\hline Hospital level of care & $\begin{array}{l}\text { District } \\
(n=28)\end{array}$ & $\begin{array}{c}\text { Regional } \\
(n=15)\end{array}$ & $\begin{array}{c}\text { Tertiary } \\
(\mathrm{n}=7)\end{array}$ & $\begin{array}{c}\text { Central } \\
(\mathrm{n}=1)\end{array}$ & $\begin{array}{c}\text { Specialise } \\
d(n=10)\end{array}$ & $\begin{array}{c}\text { Total } \\
(n=80)\end{array}$ \\
\hline $\begin{array}{l}\text { Monitoring and evaluation } \\
\text { indicators are used to } \\
\text { monitor performance }\end{array}$ & $\begin{array}{c}15 \\
(31.3 \%)\end{array}$ & $7(46.7 \%)$ & $3(42.9 \%)$ & $\begin{array}{c}1 \\
(100.0 \%)\end{array}$ & $4(44.4 \%)$ & $\begin{array}{c}30 \\
(37.5 \%)\end{array}$ \\
\hline \multicolumn{7}{|c|}{ Barriers preventing the use of monitoring and evaluation PTC indicators } \\
\hline Not aware of indicators & $\begin{array}{c}18 \\
(54.5 \%) \\
\end{array}$ & $\begin{array}{c}8 \\
(100.0 \%) \\
\end{array}$ & $2(50.0 \%)$ & NA & $5100.0 \%$ & $\begin{array}{c}33 \\
(66.0 \%) \\
\end{array}$ \\
\hline Lack of time & $\begin{array}{c}12 \\
(36.4 \%) \\
\end{array}$ & $2(25.0 \%)$ & $1(25.0 \%)$ & NA & $1(20.0 \%)$ & $\begin{array}{c}16 \\
(32.0 \%) \\
\end{array}$ \\
\hline Lack of resources & $\begin{array}{c}10 \\
(30.3 \%)\end{array}$ & $1(12.5 \%)$ & $1(25.0 \%)$ & NA & $1(20.0 \%)$ & $\begin{array}{c}12 \\
(24.0 \%)\end{array}$ \\
\hline Lack of pharmacy staff & $8(24.2 \%)$ & $2(25.0 \%)$ & $0(0.0 \%)$ & NA & $0(0.0 \%)$ & $\begin{array}{c}10 \\
(20.0 \%) \\
\end{array}$ \\
\hline Other & $6(18.2 \%)$ & $1(12.5 \%)$ & $1(25.0 \%)$ & NA & $0(0.0 \%)$ & $8(16.0 \%)$ \\
\hline $\begin{array}{l}\text { Indicators too difficult to } \\
\text { understand }\end{array}$ & $2(6.1 \%)$ & $0(0.0 \%)$ & $1(25.0 \%)$ & NA & $0(0.0 \%)$ & $3(6.0 \%)$ \\
\hline \multicolumn{7}{|c|}{ Categories of indicators being used } \\
\hline Input indicators & $8(53.3 \%)$ & $5(71.4 \%)$ & $1(33.3 \%)$ & $\begin{array}{c}1 \\
(100.0 \%)\end{array}$ & $2(50.0 \%)$ & $\begin{array}{c}17 \\
(56.7 \%) \\
\end{array}$ \\
\hline Process indicators & $7(46.7 \%)$ & $34(2.9 \%)$ & $1(33.3 \%)$ & $0.0 \%$ & $0.0 \%$ & $\begin{array}{c}11 \\
(36.7 \%)\end{array}$ \\
\hline Output indicators & $6(40.0 \%)$ & $4(57.1 \%)$ & $2(66.7 \%)$ & $0.0 \%$ & $2(50.0 \%)$ & $\begin{array}{c}14 \\
(46.7 \%) \\
\end{array}$ \\
\hline Outcome indicators & $\begin{array}{c}10 \\
(66.7 \%) \\
\end{array}$ & $3(42.9 \%)$ & $2(66.7 \%)$ & $0.0 \%$ & $3(75.0 \%)$ & $\begin{array}{c}18 \\
(60.0 \%)\end{array}$ \\
\hline Impact indicators & $8(53.3 \%)$ & $4(57.1 \%)$ & $0.0 \%$ & $\begin{array}{c}1 \\
(100.0 \%)\end{array}$ & $2(50.0 \%)$ & $\begin{array}{c}15 \\
(50.0 \%)\end{array}$ \\
\hline Section 21 item & $0.0 \%$ & $1(14.3 \%)$ & $0.0 \%$ & $0.0 \%$ & $0.0 \%$ & $1(3.3 \%)$ \\
\hline Hospital level of care & $\begin{array}{l}\text { District } \\
(n=24)\end{array}$ & $\begin{array}{c}\text { Regional } \\
(\mathrm{n}=8)\end{array}$ & $\begin{array}{c}\text { Tertiary } \\
(n=3)\end{array}$ & $\begin{array}{c}\text { Central } \\
(n=1)\end{array}$ & $\begin{array}{c}\text { Specialise } \\
d(n=6)\end{array}$ & $\begin{array}{c}\text { Total } \\
(n=42)\end{array}$ \\
\hline \multicolumn{7}{|l|}{ Use of indicators } \\
\hline Feedback to the PTC & $\begin{array}{c}21 \\
(87.5 \%) \\
\end{array}$ & $6(75.0 \%)$ & $3(100.0 \%)$ & $\begin{array}{c}1 \\
(100.0 \%)\end{array}$ & $4(66.7 \%)$ & $\begin{array}{c}35 \\
(83.3 \%) \\
\end{array}$ \\
\hline Informed decision making & $\begin{array}{c}14 \\
(58.3 \%)\end{array}$ & $3(37.5 \%)$ & $100.0 \%$ & $0.0 \%$ & $4(66.7 \%)$ & $\begin{array}{c}24 \\
(57.1 \%)\end{array}$ \\
\hline $\begin{array}{l}\text { Feedback to hospital or } \\
\text { area health services }\end{array}$ & $\begin{array}{c}13 \\
(54.2 \%)\end{array}$ & $4(50.0 \%)$ & $1(33.3 \%)$ & $\begin{array}{c}(1) \\
100.0 \%\end{array}$ & $3(50.0 \%)$ & $\begin{array}{c}22 \\
(52.4 \%)\end{array}$ \\
\hline $\begin{array}{l}\text { Feedback to Heads of } \\
\text { Departments }\end{array}$ & $\begin{array}{c}11 \\
(45.8 \%)\end{array}$ & $4(50.0 \%)$ & $2(66.7 \%)$ & $\begin{array}{c}1 \\
(100.0 \%) \\
\end{array}$ & $1(16.7 \%)$ & $\begin{array}{c}19 \\
(45.2 \%)\end{array}$ \\
\hline $\begin{array}{l}\text { Monitoring and Evaluation } \\
\text { of PTC performance }\end{array}$ & $\begin{array}{c}11 \\
(45.8 \%)\end{array}$ & $2(25.0 \%)$ & $1(33.3 \%)$ & $0.0 \%$ & (2) $33.3 \%$ & $\begin{array}{c}16 \\
(38.1 \%)\end{array}$ \\
\hline Accreditation (COHSASA) & $2(8.3 \%)$ & $0.0 \%$ & $0.0 \%$ & $\begin{array}{c}1 \\
(100.0 \%)\end{array}$ & $0.0 \%$ & $3(7.1 \%)$ \\
\hline Other (please specify) & $0.0 \%$ & $1(12.5 \%)$ & $0.0 \%$ & $0.0 \%$ & $1(16.7 \%)$ & $2(4.8 \%)$ \\
\hline
\end{tabular}

The three types of indicators mostly used among the PTCs were outcome indicators (60.0\%), input indicators (56.7\%) and impact indicators (50.0\%). Examples of indicators used in the surveyed hospitals included the following:

- Number of PTC meetings held which a quorum of members was present, per annum (output

- indicator), percentage of PTC members who attend at least $75 \%$ of meetings per annum (process

- indicator) and medicine expenditure per capita/patient (outcome indicator)

- Number of ADR reports submitted with interventions (output indicator)

- Evaluation of prescriptions for clarity and adherence to prescription standards (outcome

- indicators) 
The pharmacist $(79.1 \%)$ and secretary $(53.5 \%)$ of the PTC were identified as the individuals who would collect PTC indicator data. Other members of the PTC who collected data were quality assurance officers $(2.3 \%)$ and primary healthcare nurses (1.2\%). The most common reason for collecting PTC indicator data was to provide feedback to the PTC (83.3\%). Other reasons are shown in Table 5.

\subsection{Implementation of PTC decisions}

Nearly two thirds of the participants $(62.0 \%)$ mentioned that guidelines on implementing PTC decisions did not exist in their hospital. However, the vast majority (95.1\%) of the respondents stated that the decisions of the PTC at their hospital were implemented, typically monthly $(40.3 \%)$ or quarterly $(40.3 \%)$. Others responded that they implement decisions as required/needed/deemed necessary, as soon as possible, if a decision was agreed upon, every second month, and as decisions were made/taken (Table 6).

Table 6: Implementation of PTC decisions

\begin{tabular}{|c|c|c|c|c|c|c|c|}
\hline \multicolumn{2}{|c|}{ Hospital level of care } & District & Regional & Tertiary & Central & $\begin{array}{c}\text { Specialis } \\
\text { ed }\end{array}$ & Total \\
\hline \multicolumn{2}{|l|}{$\mathrm{n}$} & 48 & 16 & 7 & 1 & 9 & 81 \\
\hline \multicolumn{2}{|c|}{$\begin{array}{l}\text { PTC decisions are } \\
\text { implemented }\end{array}$} & $\begin{array}{c}47 \\
(97.9 \%) \\
\end{array}$ & $\begin{array}{c}13 \\
(81.3 \%) \\
\end{array}$ & $\begin{array}{c}7 \\
(100.0 \%) \\
\end{array}$ & $\begin{array}{c}1 \\
(100.0 \%) \\
\end{array}$ & $\begin{array}{c}9 \\
(100.0 \%) \\
\end{array}$ & $\begin{array}{c}77 \\
(95.1 \%) \\
\end{array}$ \\
\hline \multicolumn{2}{|l|}{$\mathrm{n}$} & 46 & 16 & 7 & 1 & 9 & 79 \\
\hline \multicolumn{2}{|c|}{$\begin{array}{l}\text { Guidelines exist on } \\
\text { implementing PTC } \\
\text { decisions }\end{array}$} & $\begin{array}{c}17 \\
(37.0 \%)\end{array}$ & $6(37.5 \%)$ & $\begin{array}{c}4 \\
(57.1 \%)\end{array}$ & $\begin{array}{c}1 \\
(100.0 \% \\
)\end{array}$ & $\begin{array}{c}2 \\
(22.2 \%)\end{array}$ & $\begin{array}{c}30 \\
(38.0 \%)\end{array}$ \\
\hline \multicolumn{2}{|l|}{$\mathrm{n}$} & 41 & 12 & 3 & 1 & 5 & 62 \\
\hline \multirow{5}{*}{$\begin{array}{l}\text { Frequency } \\
\text { of PTC } \\
\text { decision } \\
\text { implementati } \\
\text { on }\end{array}$} & Monthly & $\begin{array}{c}17 \\
(41.5 \%)\end{array}$ & $4(33.3 \%)$ & $\begin{array}{c}1 \\
(33.3 \%)\end{array}$ & $\begin{array}{c}1 \\
(100.0 \% \\
)\end{array}$ & $\begin{array}{c}2 \\
(40.0 \%)\end{array}$ & $\begin{array}{c}25 \\
(40.3 \%)\end{array}$ \\
\hline & Quarterly & $\begin{array}{c}16 \\
(39.0 \%) \\
\end{array}$ & $4(33.3 \%)$ & $\begin{array}{c}2 \\
(66.7 \%) \\
\end{array}$ & $0.0 \%$ & $\begin{array}{c}3 \\
(60.0 \%) \\
\end{array}$ & $\begin{array}{c}25 \\
(40.3 \%) \\
\end{array}$ \\
\hline & Twice a year & $2(4.9 \%)$ & $1(8.3 \%)$ & $0.0 \%$ & $0.0 \%$ & $0.0 \%$ & $3(4.8 \%)$ \\
\hline & Once a year & $\begin{array}{c}5 \\
(12.2 \%) \\
\end{array}$ & $1(8.3 \%)$ & $0.0 \%$ & $0.0 \%$ & $0.0 \%$ & $6(9.7 \%)$ \\
\hline & Never & $1(2.4 \%)$ & $2(16.7 \%)$ & $0.0 \%$ & $0.0 \%$ & $0.0 \%$ & $3(4.8 \%)$ \\
\hline \multicolumn{2}{|l|}{$\mathrm{n}$} & 48 & 15 & 7 & 1 & 9 & 80 \\
\hline \multirow{5}{*}{$\begin{array}{l}\text { Factors } \\
\text { considered } \\
\text { important } \\
\text { when } \\
\text { implementin } \\
\text { g PTC } \\
\text { decisions }\end{array}$} & $\begin{array}{l}\text { Patient } \\
\text { safety }\end{array}$ & $\begin{array}{c}46 \\
(95.8 \%)\end{array}$ & $\begin{array}{c}15 \\
(100.0 \%)\end{array}$ & $\begin{array}{c}7 \\
(100.0 \% \\
)\end{array}$ & $\begin{array}{c}1 \\
(100.0 \% \\
)\end{array}$ & $\begin{array}{c}8 \\
(88.9 \%)\end{array}$ & $\begin{array}{c}77 \\
(96.3 \%)\end{array}$ \\
\hline & Cost & $\begin{array}{c}40 \\
(83.3 \%)\end{array}$ & $\begin{array}{c}13 \\
(86.7 \%)\end{array}$ & $\begin{array}{c}7 \\
(100.0 \% \\
)\end{array}$ & $\begin{array}{c}1 \\
(100.0 \% \\
)\end{array}$ & $\begin{array}{c}8 \\
(88.9 \%)\end{array}$ & $\begin{array}{c}69 \\
(86.3 \%)\end{array}$ \\
\hline & Significance & $\begin{array}{c}35 \\
(72.9 \%)\end{array}$ & $\begin{array}{c}12 \\
(80.0 \%)\end{array}$ & $\begin{array}{c}7 \\
(100.0 \% \\
)\end{array}$ & $\begin{array}{c}1 \\
(100.0 \% \\
)\end{array}$ & $\begin{array}{c}5 \\
(55.6 \%)\end{array}$ & $\begin{array}{c}60 \\
(75.0 \%)\end{array}$ \\
\hline & $\begin{array}{l}\text { Urgency of } \\
\text { matter }\end{array}$ & $\begin{array}{c}30 \\
(62.5 \%)\end{array}$ & $\begin{array}{c}14 \\
(93.3 \%)\end{array}$ & $\begin{array}{c}6 \\
(85.7 \%)\end{array}$ & $\begin{array}{c}1 \\
(100.0 \% \\
)\end{array}$ & $\begin{array}{c}8 \\
(88.9 \%)\end{array}$ & $\begin{array}{c}59 \\
(73.8 \%)\end{array}$ \\
\hline & Other & $1(2.1 \%)$ & $0.0 \%$ & $\begin{array}{c}1 \\
(14.3 \%)\end{array}$ & $0.0 \%$ & $\begin{array}{c}1 \\
(11.1 \%) \\
\end{array}$ & $1(1.3 \%)$ \\
\hline
\end{tabular}


The reasons given by four (4.9\%) hospitals who indicated that PTC decisions were not being implemented in their hospital were the following:

- Negativity of medical practitioners as they perceive PTCs to be time consuming

- PTC decisions are not taken to the hospital management by the chairperson

- Lack of interest

When implementing PTC decisions, patient safety (96.3\%), cost $(86.3 \%)$, significance $(75.0 \%)$ and urgency of the matter $(73.8 \%)$ were regarded as important. Other reasons considered as important were clinical evidence, efficacy of medicines and availability of medicines (Table ??).

\subsection{Evaluation and review of outcomes of PTC decisions}

Two-thirds $(65.4 \%)$ of pharmacists indicated that PTC decisions were evaluated in their hospitals, with the majority stating either 'often' $(44.6 \%)$ or 'always' (33.9\%). The reasons why decisions were not evaluated in the remainder of hospitals included lack of time, not having an active monitoring and evaluation programme, lack of interest and nobody to evaluate decisions taken. In the majority of hospitals (83.8\%), PTC decisions were reviewed. Reasons for decisions not being reviewed included lack of time, not receiving feedback, believing that not all decisions needed review and lack of interest.

Half (49.3\%) of the responding pharmacists stated that the PTC decisions were 'often' reviewed and indicated that the purposes of evaluating and reviewing decisions are to monitor/measure the effectiveness of decisions taken, to monitor progress and implementation, and to ensure that decisions taken are practical, and if not, revise the decision.

\subsection{Dissemination of PTC decisions}

Figure 1 shows the different methods used by PTCs to disseminate their decisions. An email (59.5\%) was the primary means of communicating decisions, followed by personal communication (53.2\%). Other ways of communication stated were the use of minutes (7.0\%) and WhatsApp messages $(2.3 \%)$.

Figure 1: Methods of dissemination of PTC decisions ( $n=79)$

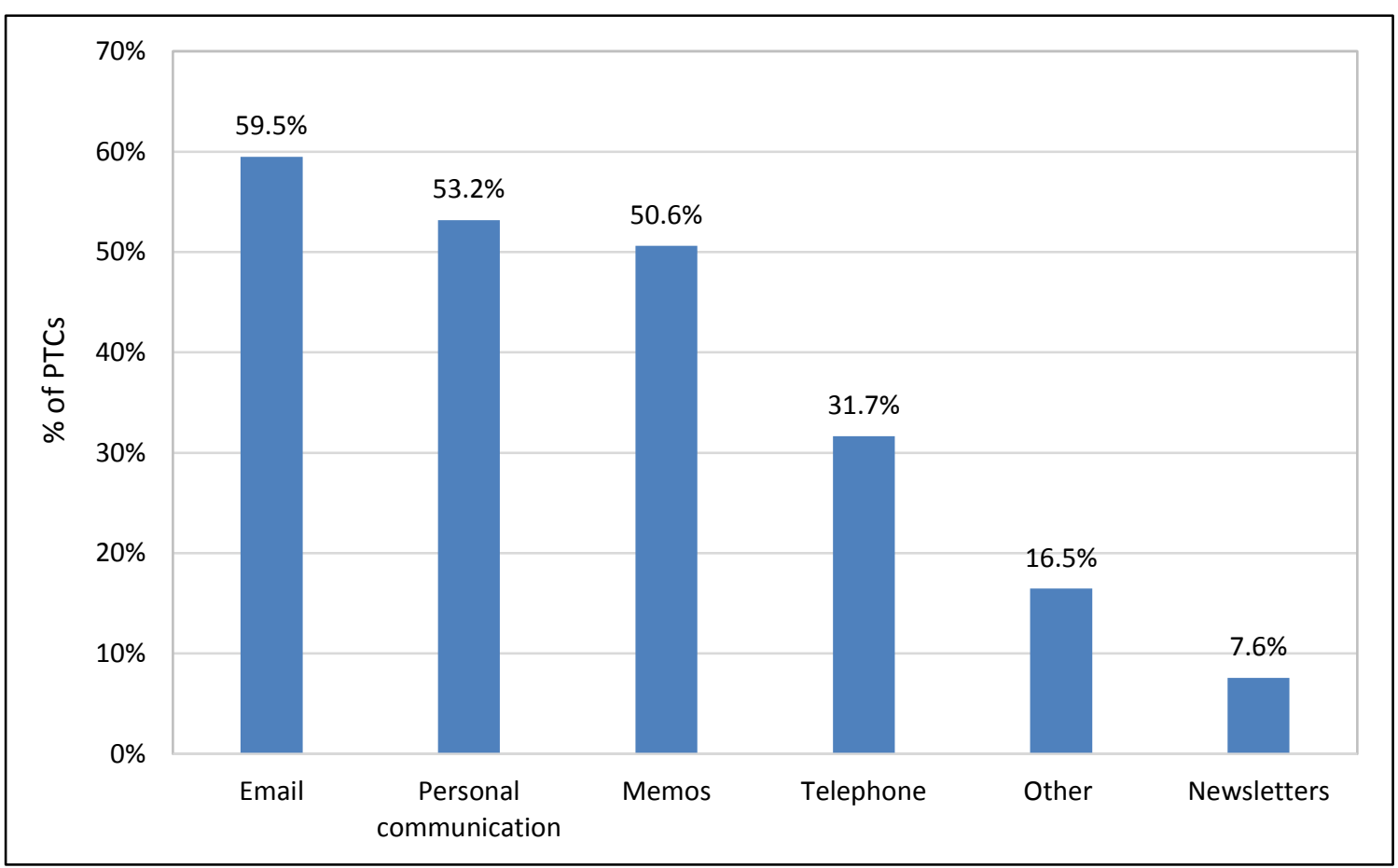




\section{Discussion}

The overall response rate was $32.3 \%$ ( 86 of 279 hospitals) despite 17 reminders being sent out. This was much lower than the study conducted in Denmark with a $100 \%$ response rate, however, only nine hospitals were targeted [33]. Our response rate was similar to that of a survey among physicians in Malaysia (34.8\%) [34], and higher though than seen among physicians taking part in web based survey in Sweden (28\%) [31] and a Canadian study where the response rate was only 24\% [20]. This may be a reflection of the large number of targeted hospitals in our survey.

Encouragingly, membership of PTCs in this study was in line with PTC guidelines [1], as well as the South African policy on PTCs which specifies that membership should include a range of expertise and skills to reflect its scope and functions [17]. Although not reported in our results, some PTCs included quality assurance officers, pharmacist assistants, clinical assistants and hospital Chief Executive Officers. The majority of pharmacists held the position of a secretary in their hospital PTCs, similar to other studies [12, 35, 36]. However, only pharmacists were invited to participate in the survey; consequently, pharmacists were represented in all PTCs taking part. Having said this, medical practitioners and nurses still had a high representation (97.6\%) in PTCs throughout public sector hospitals in the provinces in South Africa. Our findings though contrast with studies conducted in Canada, Denmark and Thailand, where physicians comprised the majority of PTC members. While pharmacists and nurses had approximately equal representation in Canada [20], most PTC members were specialist physicians (48\%), pharmacists $(12 \%)$, general practitioners $(8 \%)$ and nurses $(7 \%)$ in Denmark; and, in Thailand, the majority of PTC members were physicians with an average of two pharmacists and one nurse $[33,36]$.

Our study results show that PTCs met on average 8 times a year (range 4-12), which is in line with WHO standards, similar to our earlier study [12]. This is also similar to Canada where PTCs met on average 6.2 times per year [20] but higher than Denmark and Pakistan where PTCs meet on average four times a year $[33,35]$.

The number of members in the PTCs ranged between $11-15$ members $(30.2 \%)$ or higher $(41.8 \%)$, similar to Thailand where PTCs consisted of 13-32 members [36]. This was also comparable or higher than Canada (11 members) [20] and Australia, where the number of PTC members ranged from 2-16 [28]. The number of PTC members in our study required to form a quorum were between 6-10 members, which encouragingly was often met.

The main functions of the PTCs in our study were RMU, pharmacovigilance and Implementing STGs (Table 4). The goal of implementing STGs $(81.7 \%$ of respondents) is encouraging as implementing STGs enhances the quality of prescribing, with targets of $90 \%$ in some countries [37,38]. Our findings though differ from Canada where the principal functions of PTCs included ADR monitoring (83\%), drug-use making policy (92\%) and drug use monitoring (80\%) [20]. In Denmark, the main responsibilities and activities of the PTCs were to develop hospital drug formularies, and policies and guidelines [33], and in Thailand, the functions of the PTCs were drug evaluation and selection of medicines for the hospital formulary as well as development of drug policies [36]. However, they can potentially be seen as similar in that they all focus on medicine policies and pharmacovigilance, which are two important aspects of the PTC functions to ensure RMU.

Continuous self-monitoring of performance using indicators has been shown to improve PTC performance [36], with Vang et al. [22] suggesting that the indicators can be collected by the PTC members themselves as a means of carrying out an assessment of their performance in relation to identified tasks (standards). Whilst outcome indicators, input indicators, and output indicators were used in some of the surveyed hospitals to monitor PTC performance, principally to give feedback to PTCs (Table 5), with the pharmacist and secretary in the PTCs identified as key individuals collecting PTC indicator data, disappointingly, $63.8 \%$ of the surveyed PTCs were not using indicators to monitor PTC performance. The principal reasons for not using indicators were a lack of awareness and time (Table 6). This is a concern and will be addressed in future studies and activities as we are unaware of any previous study conducted in South Africa on the use of performance indicators among PTCs.

Considerable efforts were made to implement the decisions from the PTCs (95.1\%) despite the lack of guidelines on implementing PTC decisions in most of the PTCs surveyed. Furthermore, it could not be determined from the study which guidelines were used by the PTCs to implement their decisions. 
This was in direct contrast to a study in Denmark where little effort was made to implement PTC decisions [33]. Barriers to implementing PTC decisions included the negativity of medical practitioners as they perceived PTCs as time consuming, which needs to be addressed to improve future medicine management. This is different though from other studies where inadequate PTC structures and organizations were considered barriers to implementing decisions [39].

Suggestion to address barriers of time and importance (Table 5) include assigning a greater priority to PTC decisions, and that decisions which are assigned a high priority should be implemented first [29]. Greater education among pharmacy students, resident pharmacists, and others around PTC indicators is also recommended, and will be implemented, to address concerns with lack of knowledge and understanding. Lack of pharmacy staff can potentially be overcome through greater use of technology especially as for instance national guidelines are now readily available and updated via mobile apps [18].

In our study, patient safety, urgency, significance and cost were also considered of importance in PTC decision making, although patient safety was chosen as the most important. This is similar to other studies that reported that all respondents indicated "patient safety" as a key domain for a PTC decision and nearly one third of the respondents considered "urgency as a characteristic of decision that could grant a significant importance rating" [29, 40]. Other domains which conferred importance upon PTC decisions, included those dealing with "cost" (93\%) similar to other studies $[29,40]$.

As mentioned, a key concern in our study was the lack of time and interest in following up PTC decisions in a number of the hospitals. Encouragingly though, respondents recognized the importance of evaluating and reviewing PTC decisions, and some respondents even specified that the rationale of PTCs is to monitor the effectiveness and impact of decisions taken. Encouragingly as well is that the majority of respondents in our study stated that PTC decisions are in fact regularly evaluated and subsequently reviewed in their hospital. Evaluation of decisions enhances PTC accountability and ensures credibility of decisions taken, thereby enhancing RMU in the hospital. Other concerns included the fact that $1.9 \%$ of hospitals initially surveyed had no pharmacists and $8.5 \%$ had no PTC (Table 1). This again needs to be addressed to meet national guidelines.

In our study, emails were the primary means of communication to disseminate PTC information. Personal communication was another preferred form of communication. This is different to other studies that found that PTC decisions were principally communicated via printed material $(80 \%)$, although targeted emails were also frequently used (61\%) [20]. This though may well have changed in recent years.

We acknowledge that our response rate could raise questions about the representativeness of our data. We are also aware that we only targeted pharmacists for the survey. Another concern is that 90 hospitals could not be reached for requisitions of their email addresses due to calls not going through and pharmacists forming part of the PTC not being available during the time of study. Despite these limitations, we believe the findings are robust and provide good background information for future research and interventions.

\section{Conclusion}

Encouragingly a high number of respondents stated that the principal activities of PTCs centered around the rational use of medicines as well as seek to implement STGs, providing guidance to hospitals in other lower and middle income countries (LMICs) seeking to enhance the activities of PTCs to address concerns with the rational use of medicines in their countries. However, it was evident from our study that guidelines on implementing PTC decisions are lacking in public sector hospitals in South Africa. This needs to be addressed to enhance the effectiveness of PCTs in South Africa building on national endorsement for all hospitals to have PTCs. Such guidelines will also be useful to other LMICs as they seek to enhance PTC activities.

Whilst most decisions taken in the PTC meetings in the public hospitals in South Africa were implemented, there were typically no formal guidelines of implementing PTC decisions within the hospitals. This is another important area to address in the future among public sector hospitals as the implementation of decisions without the use of guidelines could lead to loss of accountability by PTC 
members in the long term as well as loss of information, with both potentially detrimental to the health of the patients. Again, such guidance will also be useful to other LMICs.

There are also concerns that PTCs were not routinely monitoring their performance using recognized indicators, implying that public sector hospitals in South Africa do not routinely submit PTC indicator reports as per recognized guidelines [12]. This is also an important area to address in South Africa and wider, and will be the subject of future research, as not monitoring PTC decisions also indicates that the PTC's functionality is not being routinely measured and therefore their effectiveness cannot be fully realized or determined. Nevertheless, decisions taken in these PTCs are said to be evaluated and subsequently reviewed, and we will be following this up in future research. All these gaps and challenges create room for future implementation of guidelines in all South African public sector hospital PTCs, which will guide PTCs from selecting PTC members to implementing and dissemination of PTC decisions. PTC guidelines could also be adopted from other countries that have guidelines that have strengthened their PTCs.

Overall, the results of the study can guide future amendments of hospital PTC guidelines, which is starting to happen.

\section{Key Issues}

The National Drug Policy in South Africa has strengthened PTCs through directives and guidelines. However, little is known about the implementation of such policies.

Typically, membership of PTCs in public hospitals in South Africa included pharmacists, which generally were the secretary. Principal activities of PTCs included encouraging the rational use of medicines as well as implementing STGs and pharmacovigilance activities ( $81 \%$ to $90 \%$ of hospitals surveyed for these functions). The vast majority of hospitals (95.1\%) currently implement PTC decisions; however, there was typically, a lack of guidelines on how to implement such decisions In addition, there was a lack of using indicators to monitor PTC activities and provide feedback. These concerns are being addressed

\section{Expert Commentary}

The National Drug Policy in South Africa sought to strengthen Pharmacy and Therapeutics Committees (PTCs) activities among public and private hospitals. Typically, membership of PTCs among public hospitals currently include a pharmacist, who generally hold a secretariat position. Encouragingly, the principal activities of PTCs among public hospitals include encouraging the rational use of medicines (RUM) (90.2\%), implementing standard treatment guidelines (STGs) $(81.7 \%)$ as well as undertaking pharmacovigilance $(86.6 \%)$ activities.

Whilst most decisions taken in the PTC meetings in the public hospitals are being implemented (95.1\% of hospitals), there are currently typically no formal guidelines for implementing such decisions. In addition, whilst most PTC decisions are being evaluated and reviewed, $63.8 \%$ of public hospitals are currently not using recognized indicators to monitor PTC performance. This is probably due to the lack of awareness of PTC indicators by the respondents., These are important area to address in the future to improve RMU within public hospitals in South Africa, which is starting to happen.

\section{Five-year review}

We would expect to see the principal activities of PTCs including encouraging RMU, implementation of STGs and undertaking pharmacovigilance activities to be routine within all public hospitals in South Africa. We would also expect PTC activities to be implemented and monitored, helped by the introduction of formal guidelines in all public hospitals. We would also expect all PTCs in public hospitals to be using recognized indicators to monitor their performance to further encourage RMU.

\section{Acknowledgements}

The authors would like to thank the various provincial Departments of Health and hospitals for granting approval to conduct the study in their hospitals and the public sector pharmacists part of the hospitals who participated in this study. 


\section{Author contributions}

All authors contributed in the study design. TPM developed the data collection tool with contribution from MM and JCM. TPM collected and analysed the data. All authors participated in the interpretation of the data and the study results. TPM wrote the first draft of the manuscript. All authors commented on the paper and agreed on the final version.

\section{Funding information}

This study was supported by a grant from National Research Foundation - German Academic Exchange Service (DAAD).

\section{Conflicts of Interest}

The authors declare that they have no conflicts of interest.

\section{References}

(*of importance, ${ }^{* *}$ of considerable importance)

1. Gauteng Province Department of Health. Guidelines for Implementation of Pharmaceutical and Therapeutics Committees (PTCs) in Gauteng province. $1^{\text {st }}$ ed. Pretoria; 2013. Available at URL: http://siapsprogram.org/publication/guidelines-for-implementation-of-pharmaceutical-andtherapeutics-committees-in-gauteng-province/ (Accessed 31/10/2018) ${ }^{* *}$ It outlines the selection of PTC members, reporting on PTC activities, dissemination and implementation of PTC decisions

2. National Department of Health. National Drug Policy for South Africa. Cape Town: CTP Printers; 1996. Available at URL: http://apps.who.int/medicinedocs/documents/s17744en/s17744en.pdf (Accessed 31/10/2018) * It consists of policies that set standards for legislation and regulation, drug pricing, drug selection, rational use of drugs

3. Bjorkhem-Bergman L, Andersen-Karlsson E, Laing R, et al. Interface management of pharmacotherapy. Joint hospital and primary care drug recommendations. Eur J Clin Pharmacol. 2013;69 Suppl 1:73-78.

4. Gustafsson LL, Wettermark B, Godman B, et al. The 'wise list'- a comprehensive concept to select, communicate and achieve adherence to recommendations of essential drugs in ambulatory care in Stockholm. Basic Clin Pharmacol Toxicol. 2011;108(4):224-233.

5. Godman B, Shrank W, Andersen M, et al. Policies to enhance prescribing efficiency in Europe: findings and future implications. Front Pharmacol. 2010;1:141.

6. Lima-Dellamora E, Caetano R, Gustafsson LL, et al. An analytical framework for assessing Drug and Therapeutics Committees Structure and Work Processes in Tertiary Brazillian Hospitals. Basic Clin Pharmacol Toxicol. 2014;115:268-276.

7. Fadare JO, Oshikoya KA, Ogunleye OO, et al. Drug promotional activities in Nigeria: impact on the prescribing patterns and practices of medical practitioners and the implications. Hosp Pract. 2018;46(2):77-87.

8. Civaner M. Sale strategies of pharmaceutical companies in a "pharmerging" country: the problems will not improve if the gaps remain. Health Policy. 2012;106(3):225-32.

9. Wall LL, Brown D. The high cost of free lunch. Obstet Gynecol. 2007; 110(1):169-73.

10. Datta A, Dave D. Effects of Physician-directed Pharmaceutical Promotion on Prescription Behaviors: Longitudinal Evidence. Health economics. 2017; 26(4):450-68. 
11. Spurling GK, Mansfield PR, Montgomery BD, et al. Information from Pharmaceutical Companies and the Quality, Quantity, and Cost of Physicians' Prescribing: A Systematic Review. PLoS Medicine. 2010; 7(10):e1000352.

12. Matlala M, Gous AGS, Godman B, et al. Structure and activities of pharmacy and therapeutics committees among public hospitals in South Africa: findings and implications. Expert Rev Clin Pharmacol. 2017;10(11):1273-1280.

13. Schellack N, Dlamini DN, Meyer JC, et al. Point prevalence survey of antimicrobial utilisation in an academic hospital in the Gauteng province, South Africa. Medicines Utilisation Research in Africa (MURIA). Third Training Workshop and Symposium; 2017 June 26-28; Windhoek, Namibia. Available at

URL: http://muria.mandela.ac.za/muria/media/Store/documents/Abstract\%20book\%20\%20MURAI\%203/MURIA3-AbstractBook-July-2017.pdf (Accessed 31/10/2018)

14. van der Sandt N, Schellack N, Mabope LA, et al. Surgical Antimicrobial Prophylaxis Among Pediatric Patients in South Africa Comparing Two Healthcare Settings. Pediatr Infect Dis J. 2018;Apr 19. doi:10.1097/INF.0000000000002072

15. Messina AP, van den Bergh D, Goff DA. Antimicrobial Stewardship with Pharmacist Intervention Improves Timeliness of Antimicrobials Across Thirty-three Hospitals in South Africa. Infect Dis Ther. 2015;Sep;4(Suppl 1):5-14.

16. Strengthening Pharmaceutical Systems (SPS) South Africa. Promoting the rational use of medicines through pharmaceutical and therapeutics committees in South Africa: Results, challenges, and way forward. Submitted to the US Agency for International Development by the Strengthening Pharmaceutical Systems (SPS) Program. Arlington VA: Management Sciences for Health,; 2012.

17. National Department of Health (NDoH). National policy for the establishment and functioning of Pharmaceutical and Therapeutics Committees in South Africa. Available at URL: http://www.health.gov.za/idex.php/pharmaceutical-and-therapeutics-committees * This is a more recent policy but specific just for PTCs in South Africa on establishing and functioning of PTCs.

18. Meyer JC, Schellack N, Stokes J, et al. Ongoing initiatives to improve the quality and efficiency of medicine use within the public healthcare system in South Africa; a preliminary study. Front Pharmacol. 2017;Nov 9;8:751. doi: 10.3389/fphar.2017.00751

19. Strengthening Pharmaceutical Systems (SPS) South Africa. Promoting the Rational Use of Medicines through Pharmaceutical and Therapeutics Committees in South Africa: Results, Challenges, and Way Forward. Submitted to the US Agency for International Development by the Strengthening Pharmaceutical Systems (SPS) Program. 2012. Arlington, VA: Management Sciences for Health.

20. Mittmann N, Knowles S. A survey of pharmacy and therapeutic committees across Canada: scope and responsibilities. J Clin Pharmacol. 2009;16(1):171-177.

21. Hoffmann M. The right drug, but from whose perspective? A framework for analysing the structure and activities of drug and therapeutics committees. Eur J Clin Pharmacol. 2013;69(Suppl 1):79-87. 
22. Vang C, Tomson G, Kounnavong S, et al. Improving the performance of Drug and Therapeutics Committees in hospitals-a quasi-experimental study in Laos. Eur J Clin Pharmacol. 2006;62:57-63.

23. Terblanche A, Meyer JC, Godman B, et al. Knowledge, attitudes and perspective on adverse drug reaction reporting in a public sector hospital in South Africa: baseline analysis. Hosp Pract (1995). 2017;45(5):238-45.

24. Terblanche A, Meyer JC, Godman B, et al. Impact of a pharmacist-driven pharmacovigilance system in a secondary hospital in the Gauteng Province of South Africa. Hosp Pract. 2018;46(4):221-228.

25. Naicker P, Schellack N, Godman B, et al. Creating and evaluating an opportunity for medication reconciliation in the adult population of South Africa to improve patient care. Hosp Pract. 2018;46(3):110-120.

26. Farmer BM, Nelson LS. Conflicts of interest on pharmacy and therapeutics committees at academic medical centres. J Med Toxicol. 2011;7:175-176.

27. Miralles M. Managing Access-to Medicines and Health Technologies.MDS-3rd ed. :. Arlington, VA; 2012. Chapter 48, Monitoring and evaluation, p 48.2-48.16.

28. Management Sciences for Health, World Health Organization (MSH, WHO). Drug and Therapeutics Committee Training Course. Submitted to the U.S. Agency for International Development by the Rational Pharmaceutical Management Plus Program. Arlington, VA: Management Sciences for Health; 2007. Available at www.who.int/medicines/technical briefing/tbs/Trainer-s-Guide-AllSessions.pdf (Accessed 01/11/2018) * Standard training material on PTCs in all countries

29. Tan EL, Day RO, Brien JE. Prioritising Drug and Therapeutics Committee (DTC) decisions: a national survey. Pharm World Sci. 2007;29:90-96. ${ }^{* *}$ Similar study to this study with an overview of PTC decisions and indicators used.

30. Watt SC, Simpson C, McKillop C, et al. Electronic course surveys: does automating feedback and reporting give better results? Assess Eval High Educ. 2002;27(4):325-337.

31. Eriksen J, Ovesjo ML, Vallin M, et al. Primary care physicians report high trust in and usefulness of the Stockholm drug and therapeutic committee's list of recommended essential medicines (the 'Wise List'). Eur J Clin Pharmacol. 2018;74(1):131-138.

32. MS ParerEighteenth annual conference of the Higher Education Research Society of Australasia. 1992, July 7-10 held at Monash University Gippsland Campus, Churchill Victoria

33. Plet HT, Hallas J, Nielsen GS, et al. Drug and therapeutics committees in Danish hospitals: A survey of organisation, activities and drug selection procedures. Basic Clin Pharmacol Toxicol. 2013;112: 264-269.

34. Hassali MA, Kamil TK, Md Yusof FA, et al. General practitioners' knowledge, attitude and prescribing of antibiotics for upper respiratory tract infections in Selangor, Malaysia: findings and implications. Expert Rev Anti-infect Ther. 2015;13(4):511-520.

35. Gul W. PTC is important for the betterment of the hospital pharmacy. IPP. 2014;2(1):307-311.

36. Umnuaypornlert A, Kitikannakorn N. Performance of Pharmacy and Therapeutics Committees of Public Hospitals in Rural Thailand. Mahidol University Journal of Pharmaceutical Sciences. 2014;41(1):11-18. 
37. Nakwatumbah S, Kibuule D, Godman B, et al. Compliance to guidelines for the prescribing of antibiotics in acute infections at Namibia's national referral hospital: a pilot study and the implications. Expert Rev Anti-infect Ther. 2017;15(7):713-721.

38. Niaz Q, Godman B, Massele A, et al. Validity of World Health Organisation prescribing indicators in Namibia's primary healthcare: findings and implications. Int J Qual Health Care. 2018:1-8.

39. Lima-Dellamora E, Caetano R, Gustafsson LL, et al. An analytical framework for assessing Drug and Therapeutics Committees Structure and Work Processes in Tertiary Brazillian Hospitals. Basic Clin Pharmacol Toxicol. 2014;115:268-276.

40. Duran-Garcia E, Santos-Ramos B, Puigventos-Latorre F, et al. Literature review on the structure and operation of pharmacy and therapeutics committees. Int J Clin Pharm. 2011;33:475-483. 